\title{
Quem assinou o contrato com
}

\section{o Mídia Ninja?}

Antonio Augusto Braighi ${ }^{1}$

1 Professor do Centro Federal de Educação Tecnológica de Minas Gerais (CEFET-MG) e doutorando em Estudos Linguísticos na Faculdade de Letras da Universidade Federal de Minas Gerais (FALE/UFMG). antonioaugustobraighi@gmail.com 


\section{Resumo}

A partir do conceito de Contrato de Comunicação, analisa-se a dinâmica comunicativa do Mídia Ninja com os webespectadores. Antes, a noção da metáfora é colocada à prova, seguida de uma discussão teórica que evidencia os processos de validação e pré-validação de um discurso. O intuito é verificar, após uma análise descritiva do coletivo midiático, como se dão os processos de conformação da comunicação do mesmo para atender aos parâmetros da situação comunicativa. Problematizase ainda sobre a perspectiva da interlocução e da monolocução, e a influência destas no processo de validação. Reflexões e considerações são feitas ao final acerca da emergência do novo modelo de jornalismo apresentado pelo grupo e como ele se alinha com os intentos de um determinado público.

Palavras-chave

Contrato de comunicação, validação, interlocução, mídia ninja.

\section{Abstract}

From the concept of Contract of Communication, the communicative dynamic of the Brazilian news collective Mídia Ninja with the webspectator was analyzed. First, the notion of metaphor is tested, followed by a theoretical discussion that highlights the pre-validation and validation processes of a speech. The aim is to check, after a descriptive analysis of the media collective, how its resignation processes of communication happen, in order to answer the parameters of a communicative situation. It also discusses the prospect of interlocution and of monolocution, and their influence in the validation process. Reflections and considerations are made at the end about the emergence of a new model of journalism presented by the group and how it aligns with the thoughts of a certain audience.

\section{Keywords}

Contract of communication, validation, interlocution, ninja media 


\section{Quinta-feira}

Ainda me lembro bem daquela quinta-feira. Cinco malandro em volta da fogueira. Ouvi o grito de dor de um homem que falava a verdade, mas ninguém se importava. Botando pra fora tudo o que sentiu na pele, mas ninguém lhe dava ouvidos, não.

(Charlie Brown Jr.)

Era o vigésimo dia do mês de junho de 2013. Um show da seleção espanhola de futebol contra o time do Taiti era assistido por setenta e uma mil, oitocentas e seis pessoas no Maracanã - e por milhões de outras pela televisão. Literal e metaforicamente, os europeus deram de 10 a 0 . Do lado de fora do estádio, um incontável número de manifestantes; fala-se em mais de um milhão de pessoas que tomavam as ruas não só do Rio de Janeiro, mas de boa parte do Brasil - acompanhadas por milhares de outras que assistiam aos protestos, em tempo real, pela internet. Foram registradas 388 cidades com protestos, incluindo 22 capitais brasileiras naquele dia.

Não era o começo, tampouco terminariam ali, a chamada Primavera Brasileira. Entender o significado desta nomenclatura era parte das atividades que incluíam ainda compreender o que eram PEC (e os respectivos números 33 e 37), Cura Gay, MPL, Black Bloc, Ato Médico, Occupy e que diferença fazia, afinal, 20 centavos. Não esquecendo, é claro, o que significava e representava o tal Mídia Ninja e a Pós-TV.

Sem saber muito sobre o coletivo que, pela alcunha, já demonstrava seu ativismo, me dividi naquela tarde entre observar o toque de bola do time rubro pela TV Globo e as imagens dos protestos país afora pela web. Foi o meu primeiro contato, espontâneo, com a transmissão de um grupo que já era representativo para várias pessoas, ao menos desde 2011.

A partir do início do mês de Junho de 2013, porém, o coletivo passou a ganhar um sem-número de seguidores, que paulatinamente acompanhavam as transmissões pelas redes sociais on-line. De ativistas a internautas curiosos; cidadãos, enfim. De várias idades, sobretudo jovens. Pessoas que se demonstram 
afeitas à mediação empreendida pelos Ninjas², em detrimento do trabalho da velha mídia - nas palavras de Lima (2013).

Mas, por quê? De onde vem e o que representa o apelo do Mídia Ninja? Quem consentiu ao grupo estabelecer tal vínculo? Como um veículo jovem, com uma nova proposta - diferente do jornalismo padrão (transmissão em tempo real, plano contínuo - sem cortes, com narração coloquial) - e qualidade técnica muito inferior, poderia se legitimar frente à tradição dos veículos de comunicação já estabelecidos?

Indaga-se que estas questões podem ser respondidas no bojo das discussões relacionadas à metáfora do contrato de comunicação. Nesse sentido, o propósito deste artigo é o de analisar quais seriam as principais cláusulas firmadas com o Mídia Ninja e de que forma o cumprimento delas dão manutenção ao diálogo regular estabelecido, a partir de quais processos de (pré) validação. Aproveitando o ensejo do estudo, aprofundamo-nos antes, então, nas perspectivas da translação; pode-se mesmo falar em contrato de comunicação?

\section{Dos contratos}

Pactum autem a pactione dicitur $[\ldots]$ et est pactio, duorum pluriumve in idem placitum consensus ${ }^{3}$

(ULPIANO apud BATALHA, 1981, p. 629)

A célebre expressão em epígrafe, de uso forense, atribuída ao jurista romano Eneo Domitius Ulpianus (Ulpiano), é uma das mais utilizadas para tratar da origem dos contratos - ou para se opor à concepção deles, já que contrato difere de pacto. Explica-se; representativo centro de desenvolvimento, fornecedor de diversas bases para o que se compreende como o sistema do direito contemporâneo ocidental, a Roma antiga cunhou o termo contrahere,

2 Repórteres-cinegrafistas do Mídia Ninja, nem sempre jornalistas formados. 
que em latim raso representaria "puxar (arrastar) + junto", ou que em sentido amplo estaria ligado a "amarrar" (alguém) "perto" (do credor).

Afinal, a intenção era mesmo "restringir" e "contrair" as partes, quais sejam, em que contexto fosse, às suas obrigações com o contrato. Mas é com o advento do gênero conventio, que passou a se distinguir contractus e pactum. Enquanto o primeiro devia atentar-se a toda uma ritualística e responder às configurações padronizadas em categorias formais - do documento e do processo de firma, a pacta era celebrada "sem qualquer obediência à forma, bastando o acordo de vontades. Não sendo previstos em lei, não Ihes era atribuída a proteção da actio, ou seja, se uma das partes não cumpria o prometido, a outra não poderia mover-Ihe nenhuma ação" (PETIT, 1974 apud CARVALHO, 2007, p. 230).

O leitor que já conhece a metáfora do contrato de comunicação - ou do contrato de leitura - já não questionaria o termo? Ora, o que se tem nos termos susoditos, frente, sobretudo, à literatura que incluiria como expoentes Charaudeau (2012) e Ghiglione (1983, 1984, 1986, 1988), não seria um pacto de comunicação? Nas condições acima, o contrato provavelmente estaria vinculado a situações que exijam amparo legal, cercando circunstâncias mais complexas, com investimentos vultosos de recursos ou mesmos alinhando os interesses e responsabilidades de partes que não se conhecem. Na mesma medida, o pacto estaria ligado a conjunturas mais pontuais, de menor enredamento, que não seria o caso ao ser praticado por pessoas que se conhecem.

Pacto, ao menos para a cultura ocidental, tem uma densa carga de subjetividade; talvez muito em razão da representatividade cristã. De qualquer forma, o que se compreende é que o pacto, em certa medida, ganharia mais valor e importância do que o contrato, justamente por não estar regido pelas prerrogativas da lei - estaria, então, acima dela, ou em outra instância. Não se trata de legalidade, enfim, mas de moralidade.

Entretanto, como trazer essas ideias para as relações comunicativas? É na emergência de outros tropos linguísticos (ou dos estudos de linguagem) que 
se sedimentam bases para a metáfora do contrato; alguém já não falou sobre as leis do discurso? No viés de Ghiglione (1984), a concepção de contrato de comunicação se dá a partir de duas frentes: a de que qualquer situação de comunicação é sustentada por certo número de regras, aceitas pelos parceiros da troca, delimitando o processo, e de que, então, toda situação de comunicação é resultante de um contrato portador, confeccionado pelos interesses prévios e comuns de duas partes. O contrato, com efeito, existiria para garantir a consecução dos objetivos relacionados aos interesses comuns.

Cada vez que os interlocutores encenam um mundo por meio da linguagem, eles constroem uma estrutura de mundo simples. Constroem uma estrutura de mundo com base em algumas noções fundamentais [...]. Essas noções são articuladas de acordo com um programa de lógica de criação (no interior de uma preocupação com a coerência dos textos a serem decodificados [traduzidos], ou para haver alguém que acredita em [compreende o] seu valor [consistência] cognitivo), que são encenados a um programa argumentativo para convencer o outro da base [da troca], da realidade, da verdade de um mundo como ele é feito a aparecer [a ser criado] para um indivíduo em particular (GHIGLIONE, 1988, p. 36 apud COLOMBO, 2004, p. 7).

Para além disso, um contrato é reflexivo e retroalimentativo do social, tanto quanto se alimentar de interpretações das relações socioculturais ora estabelecidas e essas constituam um quadro do contexto que influencie nos atos comunicativos que, por conseguinte, possam, a posteriori, agir novamente sobre a dinâmica social (GHIGLIONE, 1983).

Não sem motivo, para Charaudeau, o contrato deve ser aquilo que fala antes que qualquer coisa seja dita, entendido antes mesmo de ser lido (DAVID-SILVA, 2005). Para o autor há uma espécie de espaço de mediação entre os mundos do real e o de representação. O contrato de comunicação seria o espaço, então, em que se articula a finalidade comunicativa e se extrai o sentido do ato de linguagem.

E é a partir das propostas de base do ato de linguagem que Charaudeau (2012) lança mão das perspectivas circunstancial e linguageira dos contratos. Enquanto a primeira versa sobre a finalidade, tema, identidade dos sujeitos e o 
contexto de uma situação comunicativa (dados externos), a outra se alinha aos recursos de fala - comunicacionais, propriamente ditos (dados internos).

Ainda que haja negociação, os interlocutores devem reconhecer seus papéis e levar em consideração as perspectivas dos dois circuitos para que o diálogo efetivamente se estabeleça. Tem-se então uma liberdade condicionada. Nas palavras de Charaudeau (2012), "contrato de comunicação e projeto de fala se completam, trazendo, um, o seu quadro de restrições situacionais e discursivas, e outro, desdobrando-se num espaço de estratégias" (p. 71).

Vale a nota de que diversos tipos de contratos podem se agrilhoar. Um pode dar sustentação a outros mais específicos, ou até abarcá-los, tal como na relação entre o contrato de informação e o midiático. Essa coexistência pode se dar por inclusão ou entrecruzamento. De outra forma, é também na justaposição de contratos (e discursos) precedentes que podem se conformar novos discursos, ou mesmo sustentar-se o contrato da situação comunicativa em referência (BRAIGHI, 2013).

David-Silva (2005) sugere, nesse contexto, uma divisão dos contratos que se entrelaçam em um mesmo processo comunicativo, incitando que a separação pode ser feita de modo hierárquico a partir de três níveis, a saber, da base: Contrato Global de Comunicação (particularidades mais amplas do processo: finalidade, identidade dos parceiros e macrotema); Contrato Particular de Comunicação (condições gerais da interlocução); e, no topo, Variantes do contrato Global de Comunicação (especificidades das circunstâncias).

É nesse entre-dois que persiste a ideia de contrato? Mas os verdadeiros contratos não são flexíveis, não permitiriam estratégias. Ainda na carga metafórica, de outro modo, que tipo de ressarcimento a parte leitora tem se o contrato não for cumprido a contento? A ela só cabe a rescisão ou demandar (re)ajustes? Não se pode mover-Ihe nenhuma ação a não ser o rompimento com o seu interlocutor para que este do primeiro sinta falta? Nestes termos, não se poderia falar em contrato - tão somente se o for com apenas uma cláusula de descumprimento, mas sim de um pacto. 
Outro problema: muito embora, nos termos do senso comum, poder-seia questionar que tipo de pacto, este (re)validar-se-ia a cada tempo, após todo enunciado, e influenciando antes qualquer enunciação. Ao mesmo tempo, não pode haver pacto sem aquiescência natural. Sem questionamentos. E que pacto seria este que prevê uma rescisão?

\section{Da (pré)validação do acordo}

Não seria melhor falar, enfim, em um acordo? Questão para uma próxima investida, pois, invariavelmente, tomaremos aqui a expressão acordo comunicativo quando necessário. Seria acordo, pois é natural, um tanto implícito, maleável, aceita mudanças e ajustes e, ao contrário do que se prega, não obedeceria efetivamente às regras, mas as manipularia; fundaria outras a partir de um determinado quadro vigente, agindo sobre padrões socioculturais estabelecidos em cada situação comunicativa. Um compromisso temporal, sem vínculos.

De todo modo, antes de falar em contrato é preciso questionar o que leva as pessoas a se comunicarem: o reconhecimento de interesses comuns e possibilidade de alcançar objetivos específicos a partir de um processo de troca.

\footnotetext{
Uma situação é potencialmente comunicativa quando ela consegue reunir as condições necessárias para ligar os interlocutores por interesses comuns pela interação e, a partir daí, cada momento evidenciará a seleção de parâmetros contratuais (temas, maneiras de dizer, posicionamentos, saberes e valores compartilhados, socioletos, respeito a certas regras conversacionais etc.) que, objetos de avaliação recíproca, são validados (efetivando contratos) ou não validados (rompendo a interação ou exigindo ajustes) (EMEDIATO, 2007, p. 84, grifos no original).
}

Na citação, Emediato (2007) faz referência à Ghiglione (1984), autor que evidencia alguns elementos inerentes aos processos de validação que operam na dinâmica interlocutiva. Isso é, duas instâncias interlocutoras, depois de reconhecerem entre si questões de interesse (enjeux communs), estabelecem (ainda que não sejam exatamente eles que constituem, mas seja naturalmente articulada) uma Situação Potencialmente Comunicativa, que só se sedimenta com um acordo (o contrato de comunicação). 
Assim, em seguida, qualquer discurso passaria, no momento mesmo da emissão, por análises de adequação e apropriação, conformações e regulações distintas, para ser legitimado dentro de uma determinada situação comunicativa a partir do quadro de expectativas dos interlocutores e das condições particulares do contexto da troca (GHIGLIONE, 1984). O que se tem é um processo de negociação. Para Ghiglione (1988, p. 53 apud COLOMBO, 2004, p. 6), a comunicação

é um jogo que delimita [define] as apostas que os interlocutores fazem de acordo com os princípios, regras e regulamentos, cuja essência [substrato] pode ser encontrada na constância [estabilidade] dos interlocutores em relação a um único objetivo: esforço para [tentativa de] agir sobre o outro, de acordo com a estrutura de um mundo possível.

Assim, quando os parâmetros não são aceitos e/ou não estão em conformidade com as condições da Situação Potencialmente Comunicativa, há um processo de interação; artifício que, variando em razão da flexibilidade dos interlocutores, pode permitir um realinhamento dos parâmetros para que, enfim, o diálogo regular (e ora regulado) possa ser estabelecido. A Figura 1 ilustra esse movimento.

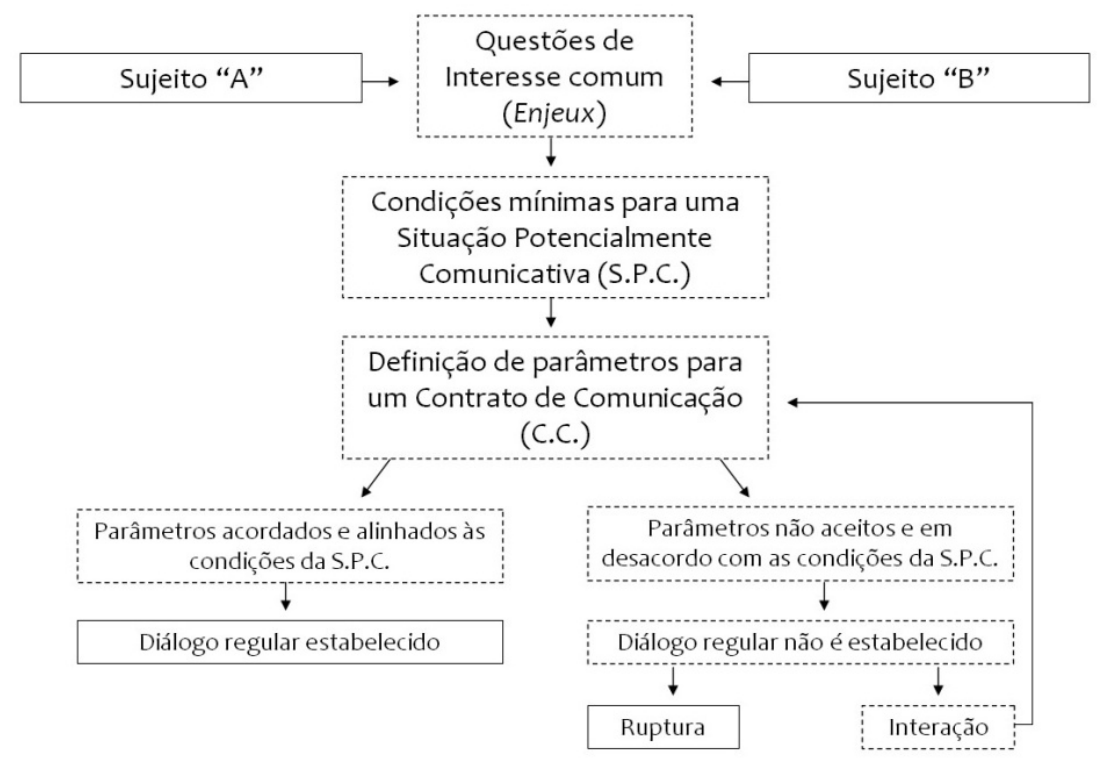

Figura 1: Da Situação Potencialmente Comunicativa ao Contrato de Comunicação Adaptado de Ghiglione (1984, p. 185) 
Quem define esses parâmetros são os próprios sujeitos. Mas é no momento mesmo das visadas, quais sejam, e das reações do outro que esses parâmetros vão sendo amalgamados. Assim, ter-se-ia a Figura 1 genérica, sendo preenchida em cada situação comunicativa a partir de acordos feitos entre as partes frente a cada investida. As regras são então apenas norteadoras; a aplicabilidade é de ordem sensível e o processo de troca é de uma complexidade tão grande que seria um erro acreditar no reducionismo do conjunto de regras e não em um conjunto de possibilidades no qual está contido o universo dos possíveis. Assim, "a esperança é conseguir conciliar a determinação do discurso e a liberdade dos sujeitos, em torno de um sistema de convenções que ordena um jogo de cooperação e rivalidade" (JEANNERET; PATRIN-LECLÈRE, 2004, p. 134, tradução minha).

Isso tudo parece mais claro em processos interlocutivos, em que um determinado locutor recebe retroação imediata do alocutário, de diversas formas. A questão se complexifica em situações monolocutivas - jornais e revistas, livros, discursos, publicidade, entre muitas outras em que não há interação imediata e direta. Para estas, compreende-se que o locutor primeiro imbrique a S. P. C. com o C. C., entendendo que já há interesse comum de outros e uma pré-validação do seu modo de delineamento do discurso. Para tanto, o locutor deve levar em consideração, para o arranjo do seu texto, as competências que o alocutário tem (ou deveria ter) para compreendê-lo. Estas são de ordem axiológica, praxeológica, referencial e linguística (GHIGLIONE, 1984; EMEDIATO, 2007).

O problema que a internet parece apontar, nesse meandro assentado por Ghiglione (1984), é justamente o de situações semi-interlocutivas ou extramonolocutivas. Com exceção das ferramentas modelo chat, as plataformas web de comunicação/informação são essencialmente monolocutivas. Entretanto, é imperativa na rede a interação. Esta, todavia, circunscrita muitas vezes logo abaixo de boa parte das publicações em redes sociais on-line, tais como o Facebook. Em alguns casos, são formados verdadeiros fóruns em torno do post primeiro. 
Em geral, a monolocução se estabelece no formato um para muitos. Apesar de a internet ofertar um retorno (quase imediato) da audiência pós-post, este, entretanto, guardadas as proporções de velocidade/agilidade, pode nos lembrar das cartas dos leitores, ou mesmo o feedback dos votos nas urnas, a aquisição de livros e outros produtos nas lojas, o público nas sessões das peças, entre outros.

Exemplo prático da vida prosaica: no momento mesmo da produção deste artigo (janeiro de 2014), no Facebook, um colega resolveu postar a sua indignação quanto à campanha para arrecadar fundos para que o ex-deputado José Genoíno pagasse a multa referente ao processo do mensalão. Os likes que ele recebeu servem de validação? Vendo os comentários, leem-se questionamentos não só da posição do face friend, mas do que ele digitou (a construção do discurso) penso eu que muitos esperavam esse posicionamento dele, mas poucos de como ele articulou o discurso (de forma pejorativa e com palavras de baixo calão). Será que ele vai apagar o post? Será que alguém irá excluí-lo? Troca-se o endereço, e veem-se os comentários de internautas em uma reportagem do G1 sobre o mesmo tema: "Este texto é tendencioso"; "A Globo não tem envergadura moral para falar do PT". O texto será alterado? Aliás, o texto será apagado? Enfim, o que se quer com este exemplo é questionar se há direto e efetivo processo de regulação e conformação, ainda que haja alguma interação pós-post.

Vale lembrar que Mininni (2004) já nos apresentou o conceito de contrato de comunicação virtual; ao analisar a dinâmica na internet, o autor registra que a comunicação neste universo obrigaria os sujeitos a agenciarem múltiplos aspectos do eu. Isso é, a compressão da web incitaria os sujeitos a gerirem diferentes posições discursivas, fazendo-os, num passo, marcarem sua identidade e, de outro, uma relativização em cada situação.

Apesar disso, nos dois casos exemplificados anteriormente, interessante é perceber que, no mesmo espaço aberto para comentários de internautas, o locutor primeiro (tanto o meu colega, quanto o G1), poderiam também responder, gerenciar, negociar - se o quisessem, pois não o fizeram. Também poderiam 
apagar os comentários dos terceiros, aqueles que não os agradavam ou não validavam a postagem (ao menos o meu colega não o fez, acredito). Semiinterlocução ou extramonolocução? Poder-se-ia falar então de uma interlocução pós-monolocutiva?

De qualquer forma, a complexidade existe em medida maior não na realização locutor/alocutário, ou na dinâmica monolocutiva, mas na perspectiva comunicativa do um para um frente a um para muitos, esta última em que a figura imaginária do destinatário idealizado encontra-se embaçada pelos múltiplos planos de expectativa de uma recepção qualquer heterogênea.

No entanto, a internet tem condições de ofertar uma monolocução um para muitos com efetiva interatividade (feedback + negociação para validação) no momento mesmo da produção do discurso. Se esta se torna uma (semi) interlocução ou se mantém como um processo (extra) monolocutivo, assim como de que maneira esta dinâmica se dá, é o que será visto a seguir, a partir de uma análise pontual de parte da dinâmica do Mídia Ninja.

\section{Mídia Ninja}

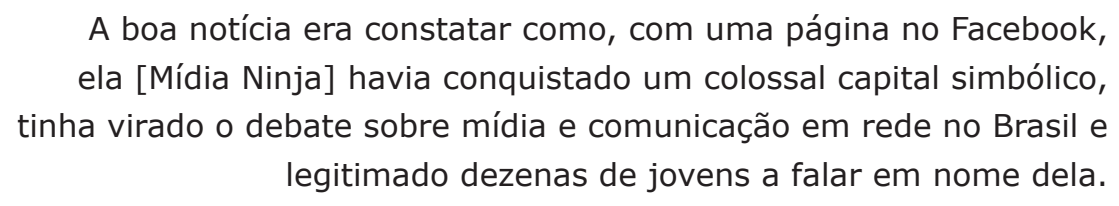

(Bruno Torturra, 2015)

A Narrativas Independentes, Jornalismo e Ação é uma rede de jornalismo independente composta por pessoas imbuídas da perspectiva de noticiar temáticas relacionadas às causas sociais, quais sejam, por intermédio da veiculação de textos, fotos, vídeos e transmissões simultâneas em uma página no Facebook ${ }^{4}$ e em plataformas específicas ${ }^{5}$. Aliás, esse era o propósito inicial do grupo que 
nasce das articulações do Coletivo Fora do Eixo ${ }^{6}$. Nas palavras de Bruno Torturra, um dos fundadores do Mídia Ninja, após as manifestações que tomaram o Brasil em junho e julho de 2013, "por mais que tentássemos, não éramos mais um veículo, mas uma estética, uma modalidade de jornalismo que se confundia com ativismo" (TORTURRA, 2013).

É por meio do trabalho desta mídia independente que é possível acompanhar eventos, em tempo real, de toda ordem, isso é, em primazia manifestações em geral. Hoje, basta que os Ninjas tenham um smartphone, ou algo que o valha com acesso à internet e uma câmera, para transmitirem os acontecimentos em (live) streaming ${ }^{7}$ para os webespectadores que os acompanham.

Uma das principais características do Mídia Ninja é o declarado posicionamento nas coberturas. Os repórteres não apenas registram, mas são ativos partícipes dos eventos - em acordo com a designação qualificativa do coletivo. O mesmo pode ser compreendido a partir das perspectivas do ativismo midiático, ou do midialivrismo ciberativista.

Como norte principal, então, se posicionariam e agiriam a favor da total liberdade de expressão; em defesa da produção livre de conteúdo - aquém de qualquer hierarquia; contra o modo de produção de informação de grandes conglomerados midiáticos; em prol de uma maior participação da sociedade civil na criação de conteúdos midiáticos e de novos processos compartilhados de comunicação (colaboração social em rede), entre outras frentes, incluindo, principalmente, diferentes enquadramentos e narrativas sobre um mesmo fato (haja vista que qualquer fato é extralinguístico) (MALINI; ANTOUN, 2013). Nesse contexto, o midialivrista poderia ser considerado

o hacker das narrativas, um tipo de sujeito que produz, continuamente, narrativas sobre acontecimentos sociais que destoam das visões [...] de grandes conglomerados de comunicação. [...] Essa narrativa hackeada, 
ao ser submetida ao compartilhamento do muitos-muitos, gera um ruído cujo principal valor é de dispor uma visão múltipla, conflitiva, subjetiva e perspectiva sobre o acontecimento passado e sobre os desdobramentos futuros de um fato (MALINI; ANTOUN, 2013, p. 23).

Isso o Mídia Ninja faz com a propriedade de jovens que se identificam com as causas-tema dos acontecimentos sociais que cobrem, quais sejam, de apelo e interesse social, a partir de um quadro de sentidos criado a reboque da mise-enscène telemática. A locução, com todo o coloquialismo de contexto, ora em narrativa descritiva - num estabelecimento de diálogo com a audiência -, ora evidenciando as trocas do Ninja com os outros atores da cena do acontecimento (confundindo as barreiras dêiticas), é capaz também de produzir efeitos patêmicos tanto quanto os enquadramentos subjetivos de uma câmera irrequieta, que permitiria, na mesma medida, transpor quem assiste ao local de produção.

Quanto ao público, o que se tem, em geral, são internautas que interagem com o universo de dados da rede, produzindo, também, informação. Para Malini e Antoun (2013), "a internet de hoje se transmutou, sem dúvida. A atuação social, a mobilização e o engajamento viraram um valor da rede, contrapondo aquele pensamento de felicidade eterna da web comercial, que contaminava a economia e a política" (p. 152).

Nesse contexto, o Mídia Ninja encontra vasto campo de espectadores em potencial. Sujeitos que, de qualquer lugar do país, demandariam um pertencimento às causas ora enquadradas pelas lentes dos Ninjas e se veriam inseridos no processo de mobilização pública, ainda que de forma mediada, a partir da lida de um coletivo de mídia voluntário e ativista. É importante dizer que há mecanismos de interação desse sujeito espectador com o repórter-ninja. A principal plataforma de transmissão em tempo real, o TwitCasting ${ }^{8}$, tem uma espécie de chat no qual a audiência pode enviar opiniões, sugestões, críticas e até mesmo estabelecer conversas entre os internautas que estão on-line. 


\section{A (pré)validação do acordo com o Mídia Ninja}

O Mídia Ninja foi criado com uma proposta, diria eu, editorial, clara. Seu público é (pode ser) qualquer um interessado na cobertura de acontecimentos diversos, mas se consolidou, principalmente, com pessoas que, para além de um voyeurismo evenemencial, se envolviam, acreditavam ou preocupavam-se com uma determinada causa. É sob a égide desse público (acredita-se ainda cativo) que se estruturou o contrato do coletivo.

Entretanto, houve (e ainda há) uma pré-validação do discurso do Mídia Ninja. O grupo teve que elaborar as suas investidas a partir do reconhecimento de um determinado tipo de público que poderia se interessar pelas coberturas. De modo geral, esse público seria justamente formado por (ciber)ativistas. Sujeitos que, reconhecidas as afinidades com o coletivo, conseguiriam fazer funcionar uma Situação Potencialmente Comunicativa. Por compartilharem de uma mesma perspectiva política (no sentido mais amplo do termo), esse conjunto de ativistas da/na internet teriam ainda competências que seriam facilitadoras da adesão ao contrato e da compreensão do discurso elaborado pelo Mídia Ninja.

Ainda que com linguagem nova e diferenciada, o coletivo teve, no entanto, que respeitar um quadro referencial que the imputava certos limites e/ou condicionamentos. Isto é, apesar da abordagem particular, o Mídia Ninja segue os parâmetros de um discurso e de um contrato [pacto ou acordo], primeiro de informação (dentro do qual se desenvolvem as particularidades midiáticas, incluindo as dos veículos que se proliferam na internet), que se amalgama a outro parâmetro de ativismo, conforme a Figura 2 apresenta. 


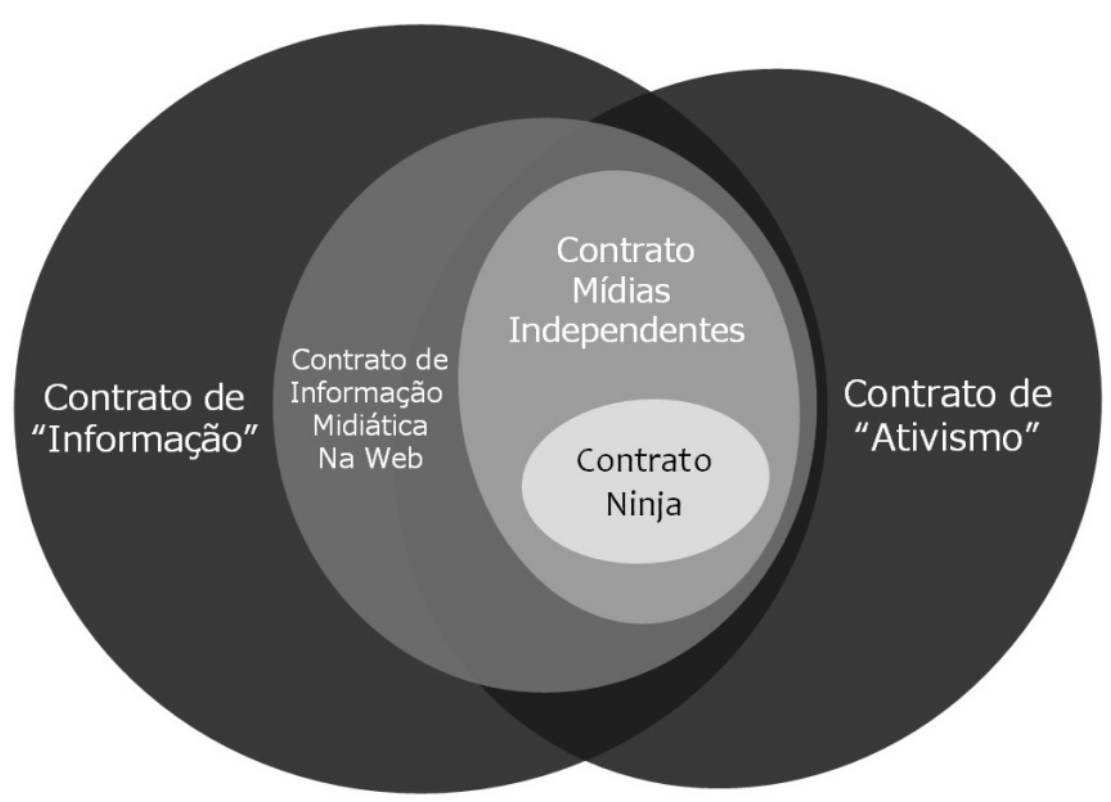

Figura 2: Contratos encadeados

Essas esferas, no entanto, estão sempre em movimento, se chocando, em alguns momentos se repelindo, sobretudo com a inserção de novos elementos ao contexto. Isso é, não é só a inserção de alocutários com competências limitadas na situação comunicativa que poderia gerar problemas. No caso específico do Mídia Ninja, a reverberação de uma entrevista concedida ao programa Roda Viva e as acusações feitas por ex-integrantes ${ }^{9}$ do Fora do Eixo colocaram em dúvida a idoneidade do coletivo. De todo modo, fala-se primeiro em pré-validação do discurso do jornalismo independente. É justamente a nova linguagem de cobertura que interessaria, uma vez atrelada a um grupo voluntário que, abertamente, demonstra um posicionamento ativo frente às coberturas que faz.

Vale ressalvar que de certa maneira o Mídia Ninja consegue estabelecer um processo interlocutivo que acaba se tornando um chat, no TwitCasting, muito embora, em tese, poderia gerar interatividade e validação no momento mesmo de uma cobertura, com a funcionalidade comentários. 
Com feedback do webspectador pari passu à transmissão, o Ninja pode responder, na própria apresentação/locução, aos possíveis questionamentos, solicitações, críticas, até elogios. Essa resposta refere-se não apenas à literalidade do ato verbal, mas à ação com um enquadramento de câmera ou a uma determinada abordagem ou investida do ativista-repórter, entre outras ações.

Nesse sentido, estabelecer-se-iam dois processos comunicativos complexos, paralelos e cíclicos na transmissão: o primeiro, fundante, molocutivo, no sistema um para muitos (Ninja-webespectadores), pré-validado; o segundo de resposta, retroativo, composto, monolocutivo, no sistema muitos para um. O primeiro age diretamente sobre a constituição do segundo, podendo ser influenciado por ele, regulando-se e conformando-se, apesar de novamente ter condições de fazer girar o ato - negociando e agenciando estratégias diversas. O segundo, em sua composição, é por um lado o sentido-extrato de sua autointeração (entre os internautas) e, por outro, resultado de intentos diversos e isolados dos partícipes do chat, ambos gerando efeitos distintos e múltiplos sobre a transmissão e constituindo-se sob a dinâmica da mesma.

Isso nos referindo apenas aos processos comunicativos que se estabelecem a partir da plataforma em questão. Como dito anteriormente, tanto o Mídia Ninja quanto os respectivos seguidores têm à disposição um grande número de redes sociais on-line a partir das quais podem multiplicar, discutir, questionar ou endossar a dinâmica do acontecimento enquadrado e o próprio enquadramento midiático.

Assim, aferir se o Mídia Ninja é semi-interlocutivo ou extramonolocutivo é apenas uma parte da discussão que ora se apresentou; mesmo porque uma resposta conclusiva dependeria de um exame mais detalhado a partir de um determinado recorte. O que o trabalho do coletivo acaba por fazer é detonar uma complexa cadeia de relações comunicativas que são cíclicas e retroalimentativas, o que extrapola as particularidades do acordo. 


\section{Quem assinou o acordo com o Mídia Ninja?}

A função primeira do jornalismo é informar, levando em consideração critérios básicos como imparcialidade, objetividade e verdade. É o que se ensina na graduação. Na prática, é uma relativa utopia (BRAIGHI, 2013). E isso jornalistas e leitores, quais sejam, já sabem bem. Talvez o que mais se espera do jornalismo hoje é que ele cumpra efetivamente a sua função social e reconsidere os critérios de valor-notícia; isso é, em detrimento da busca incessante da notícia sobre o "homem que mordeu o cachorro", que a área represente o enfrentamento, para a construção da cidadania.

Ao menos institucionalmente há, por parte da mídia tradicional, essa defesa, aguardada também pelos seus alocutários. Se não o fosse, as manifestações não bradariam tanto contra os grandes veículos de comunicação. Talvez não esteja sendo cumprido o pacto. Talvez seja exatamente nessa lacuna que as mídias independentes encontram terreno fértil para se desenvolver, fazendo valer e assumindo um contrato que a audiência tinha com as grandes corporações midiáticas.

Mas qual seria a diferença então do Mídia Ninja para as outras mídias? Conjectura-se que esteja na interseção da militância com a informação e na materialização do discurso ativista representado no agir nas manifestações para além do fazer jornalístico. Assim, compõe-se uma banca webespectadora formada por indivíduos que fazem valer o seu pertencimento (indaga-se) às manifestações, não apenas em razão de uma transmissão em tempo real e sem cortes, mas em função da identificação com os Ninjas - pois eles não somente narram o acontecimento, como também o experimentam e manipulam efetivamente enquanto o transmitem. O acordo estaria funcionando: informação + ativismo. 
A mídia independente molda o seu discurso em alguns alicerces históricos, adaptando-os à realidade contemporânea. Essas fundações são também de ordem ideológica na medida em que se filiam a uma análise crítica da mídia tradicional, da organização social e da dinâmica política, fazendo agir uma prática jornalística que diferencia o locutor e cria sentidos para a sua prática (jornalismo ação, e toda a carga subjetiva que está a reboque). É claro que tudo isso tem a ver também com o gênero da emissão, com o ethos construído pelo veículo, o pathos de seu público, com efeitos visados diversos agenciados, entre outras variáveis.

Ninguém assinou um contrato com o Mídia Ninja. O objeto da relação já existia. Faltava apenas uma parte que se interessasse em assumir e responder por tal. Entretanto, parece haver hoje mais do que um acordo do coletivo com os seus seguidores. Nos termos utilizados neste artigo, nos alvitramos a dizer que há um pacto, e pactos devem ser cumpridos e respeitados ${ }^{11}$. 


\section{Referências}

BATALHA, W. S. C. Introdução ao estudo do direito: os fundamentos e a visão histórica. Rio de Janeiro: Forense, 1981.

BRAIGHI, A. A. Análise de telejornais: um modelo de exame da apresentação e estrutura de noticiários televisivos. Rio de Janeiro: E-papers, 2013.

CARVALHO, F. V. O pensamento político monarcômaco: da limitação do poder real ao contratualismo. Tese (Doutorado em Filosofia) - Faculdade de Filosofia, Letras e Ciências Humanas, Universidade de São Paulo, São Paulo, 2007.

CHARAUDEAU, P. Discurso das mídias. São Paulo: Contexto, 2012.

CHARLIE BROWN JR. Quinta-feira. Composição de Alexandre Magno Abrão (Chorão). In: TRANSPIRAÇÃO CONTÍNUA PROLONGADA. São Paulo: Virgin, 1997. Faixa 9 (4 $\min 50 \mathrm{~s})$.

COLOMBO, M. Theoretical perspectives in Media-Communication Research: From Linear to Discursive Models. Qualitative Social Research, v. 5, n. 2, 2004. Disponível em: <http://www.qualitative-research.net/index.php/fqs/article/ view/592/1286>. Acesso em: 10 nov. 2014.

DAVID-SILVA, G. A informação televisiva: uma encenação da realidade. Tese (Doutorado) - Faculdade de Letras, Universidade Federal de Minas Gerais, Belo Horizonte, 2005.

EMEDIATO, W. Contrato de leitura, parâmetros e figuras de leitor. In: MARI, H.; WALTY, I.; FONSECA, M. N. S. (Org.). Ensaios sobre Leitura 2. Belo Horizonte: PUCMINAS, 2007. p. 83-98. 
GHIGLIONE, R. Système de communication-contrats de communication. Paris: Champs Educatifs, 1983.

GHIGLIONE, R. Situations potentiellement communicatives et contrats de communications éffectifs. Revue Verbum, Nancy, v. 2, tome VII, p. 185-208, 1984.

GHIGLiONE, R. L'Homme Communiquant. Paris: A. Colin, 1986.

GHIGLIONE, R. La comunicazione è un contratto. Bari: Liguori, 1988.

JEANNERET, Y.; PATRIN-LECLÈRE, V. La métaphore du contrat. Hermès, Paris, n. 38 , p. $133-140,2004$.

LIMA, V. Mídia, rebeldia urbana e crise de representação. In: MARICATO, E. (Org.). Cidades rebeldes: Passe Livre e as manifestações que tomaram as ruas do Brasil. São Paulo: Boitempo, 2013.

MALINI, F.; ANTOUN, H. A internet e a rua: ciberativismo e mobilização nas redes sociais. Porto Alegre: Sulina, 2013.

MININNI, G. Les contrats de la communication virtuelle. In: BROMBERG, M.; TROGNON, A. (Org.). Psychologie sociale et communication. Paris: Dunod, 2004. p. $121-131$

TORTURRA, B. Olho da rua. Revista Piauí, São Paulo, ed. 87, dez. 2013. Disponível em: <http://revistapiaui.estadao.com.br/materia/olho-da-rua/>. Acesso em: 29 out. 2015.

submetido em: 11 nov. 2014 | aprovado em: 09 fev. 2015 